\title{
The level of claudin-7 is reduced as an early event in colorectal carcinogenesis
}

\author{
Jette Bornholdt', Stine Friis', Sine Godiksen², Steen S Poulsen³, Eric Santoni-Rugiu ${ }^{4}$, Hanne C Bisgaard', \\ Inger MB Lothe ${ }^{5}$, Tone kdahl $^{6}$, Kjell M Tveit ${ }^{6}$, Egil Johnson ${ }^{7,8}$, Elin H Kure ${ }^{9,10}$, Lotte K Vogel ${ }^{1^{*}}$
}

\begin{abstract}
Background: Compromised epithelial barriers are found in dysplastic tissue of the gastrointestinal tract. Claudins are transmembrane proteins important for tight junctions. Claudins regulate the paracellular transport and are crucial for maintaining a functional epithelial barrier. Down-regulation of the oncogenic serine protease, matriptase, induces leakiness in epithelial barriers both in vivo and in vitro. We found in an in-silico search tight co-regulation between matriptase and claudin-7 expression. We have previously shown that the matriptase expression level decreases during colorectal carcinogenesis. In the present study we investigated whether claudin-7 expression is likewise decreased during colorectal carcinogenesis, thereby causing or contributing to the compromised epithelial leakiness of dysplastic tissue.
\end{abstract}

Methods: The mRNA level of claudin-7 (CLDN7) was determined in samples from 18 healthy individuals, 100 individuals with dysplasia and 121 colorectal cancer patients using quantitative real time RT-PCR. In addition, immunohistochemical stainings were performed on colorectal adenomas and carcinomas, to confirm the mRNA findings.

Results: A 2.7-fold reduction in the claudin-7 mRNA level was found when comparing the biopsies from healthy individuals with the biopsies of carcinomas $(p<0.001)$. Reductions in the claudin-7 mRNA levels were also detected in mild/moderate dysplasia $(p<0.001)$, severe dysplasia $(p<0.01)$ and carcinomas $(p<0.01)$, compared to a control sample from the same individual. The decrease at mRNA level was confirmed at the protein level by immunohistochemical stainings.

Conclusions: Our results show that the claudin-7 mRNA level is decreased already as an early event in colorectal carcinogenesis, probably contributing to the compromised epithelial barrier in adenomas.

\section{Background}

DNA damage promotes carcinogenesis. This is clearly seen when DNA repair mechanisms are compromised. The eukaryotic cell takes many measures to prevent DNA damage, including formation of physical barriers to prevent the entry of carcinogens and other substances into the organism. In the gastrointestinal tract, a layer of polarised epithelial cells, held together by tight junctions and covered by a layer of mucus, forms a surprisingly efficient barrier. However, this barrier is often compromised already in dysplastic tissue [1]. This is likely to be

\footnotetext{
* Correspondence: vogel@sund.ku.dk

'Department of Cellular and Molecular Medicine, Faculty of Health Science, University of Copenhagen, Denmark

Full list of author information is available at the end of the article
}

a factor driving carcinogenesis by allowing carcinogens to enter the underlying tissue.

In the intestine, molecules may pass the monolayer of epithelial cells, either by the transcellular route involving transcytosis or by the paracellular route crossing the tight junctions. Tight junctions are primarily located at the apical end of the lateral plasma membrane [2]. In addition to controlling the paracellular diffusion, tight junctions prevent the diffusion of membrane proteins and lipids between the apical and the basolateral plasma membrane domains [3]. Tight junctions are formed mainly by three types of integral proteins: occludins, junctional adhesion molecules and claudins [4]. In total, 24 different mammalian claudins have been described [5]. The composition of claudins in the tight junction complex is thought to dictate the permeability of the

\section{Biomed Central}


epithelium by regulating the permeability of the tight junctions $[4,6]$. The expression levels of various claudins in a tissue can change according to physiological and pathological conditions, thereby altering the permeability of the epithelial barrier [7].

Connections of tight junctions between cells are made by interactions between the extracellular loops of the claudins. However, the molecular mechanisms and the exact stoichiometry behind the assembly of tight junctions are poorly understood [8]. The majority of claudins are known to increase the epithelial tightness by sealing the tight junctions. Claudins like claudin-1, -4 , $-5,-7,-8,-11,-14$, and -19 are considered sealing claudins, as increased expression of these leads to increased epithelial tightness [6,9-12]. Other claudins are able to form paracellular anion- and cation pores as well as water channels [5,13]. Claudin-2, -10 , and -16 are examples of pore-forming claudins known to decrease epithelial tightness when expression is increased.

The serine protease matriptase plays an important but, as yet, poorly defined role in the generation and maintenance of epithelial barriers. Matriptase, encoded by the ST14 gene, is expressed in most epithelial cells [14] and its proteolytic activity is tightly regulated by at least two membrane-bound inhibitors, HAI-1 (SPINT1) and HAI2 (SPINT2) [15-17]. Ablation of the ST14 gene in mice generates a phenotype with compromised epithelial barrier function and fatal outcome $[18,19]$. In addition, dysregulated matriptase expression as investigated in transgenic mice has been shown to have a very strong oncogenic potential [15]. A study using the colonic adenocarcinoma cell line Caco-2, which spontaneously form tight monolayers of polarized cells, when grown on filters, showed that siRNA-induced down-regulation of matriptase resulted in compromised epithelial barrier function [20].

We have previously shown that the mRNA level of matriptase and its inhibitors are significantly downregulated during colorectal carcinogenesis [21,22]. Still, the molecular mechanism whereby the proteolytic activity of matriptase affects the epithelial barrier is unknown. In the search for downstream effectors of matriptase, we made an in-silico array based study to identify genes co-regulated with the matriptase gene, ST14. The analysis showed that besides the already known inhibitor of matriptase, HAI-1 encoded by SPINT1, CLDN7, encoding claudin-7, is the gene most tightly co-regulated with the ST14 gene. Claudin-7 belongs to the class of claudins promoting epithelial tightness [10-12] and is found in most epithelia, for instance in the airways [23], the intestines [24,25], the Loop of Henle and the collecting duct of the kidney [8]. Claudin-7 is involved in regulation of the permeability of $\mathrm{Cl}^{-}$and $\mathrm{Na}^{+}$ions. Recently, claudin-7 knockout mice were generated and shown to have a normal phenotype at birth. However, within days they developed chronic dehydration, leading to a fatal outcome 12 days after birth [12].

In the present study, we investigated the levels of claudin-7 mRNA during colorectal carcinogenesis and found that claudin-7 mRNA is significantly decreased in mild/moderate dysplasia, severe dysplasia and carcinomatous tissue. The decrease in claudin-7 level could also be confirmed at the protein level.

\section{Methods}

\section{In-silico co-expression array database study}

The COXPRESSdb version 4.0 located at http:// coxpresdb.jp/[26] was used to identify genes co-regulated with matriptase. All expression data for this database are based on affymetrix GeneChip, information which has been released by NCBI GEO. The analysis was performed using default settings entering ST14 as gene symbol in the gene search tool. In the results, the ST14 icon under the human gene search was selected. Expression similarity for ST14 in relation to all other genes in the database was calculated using Pearson's correlation coefficient and ranked. The opposite correlation coefficients where also calculated and ranked. To evaluate the strength of co-expression a mutual ranking $(M R)$ value was calculated using the formula $M R_{(A B)}=$ $\left(\operatorname{rank}_{(\mathrm{A} \rightarrow \mathrm{B})}{ }^{*} \operatorname{rank}_{(\mathrm{B} \rightarrow \mathrm{A}))} 0.5\right.$. The lower the MR value the higher the co-expression.

\section{Human tissue samples}

The tissues used in this study have previously been described [22]. In short, the KAM cohort is based on a screening performed in the Norwegian Colorectal Cancer Prevention study (NORCCAP) in the county of Telemark, Norway [27] with the ID number NCT00119912 at Clinicaltrials.gov. In addition, a series of colorectal cancer (CRC) cases was recruited to the cohort from Telemark Hospital in Skien and Ulleval University Hospital in Oslo. The KAM study is approved by the Regional Committee for Medical Research Ethics and the Norwegian Data Inspectorate. In the present study, we analysed 121 cases with carcinoma, 100 cases with adenomas and 18 healthy individuals. From individuals with adenomas, control tissue was sampled $30 \mathrm{~cm}$ above the anus. From patients with carcinomas, two control samples were taken from the surgically removed specimen. One sample was taken adjacent to the cancer (normal adjacent) and the other sample was taken as distant from the cancer as possible (normal distant). The histology of the adenomas was examined independently by two histopathologists, who categorised the degree of dysplasia as either mild/moderate $(n=87)$ or severe $(n=13)$. Consensus was 
reached in all cases. Cases of dysplasia were also classified as either low- or high-risk according to the size and/or differentiation state of the adenoma. A high-risk adenoma is defined as an adenoma measuring $\geq 10 \mathrm{~mm}$ in diameter and/or with villous components or showing severe dysplasia [27]. Carcinomas were classified according to Dukes staging. The distribution of gender and age among individuals included in the study is shown in Table 1.

Real-time reverse transcriptase polymerase chain reaction The tissue samples were frozen as soon as possible after surgery and stored in liquid nitrogen until RNA purification. Total RNA was purified from tissue as recommended by the manufacturer using E.Z.N.A. Total RNA Kit II (cat. no. R6834-02, Omega Bio-Tek) and the RNase Free DNase kit I (cat. no. E1091-01). cDNA synthesis was performed on approximately 200 ng RNA per $20 \mu \mathrm{l}$ using the High-Capacity cDNA Archive Kit (cat. no. 4375222, Applied Biosystems). Quantitative real time RT-PCR for claudin-7 was performed on the ABI7300 sequence detection system (Applied Biosystems) in Universal PCR Master Mix (cat. no. 4326614, Applied Biosystems) using $250 \mathrm{nM}$ probe and $300 \mathrm{nM}$ primers. Primers and probe were: $C L D N 7$ forward 5'-ATGATGAGCTGCAAAATGTACGA-3'; CLDN7 reverse 5'-GCACCAGGGAGACCACCAT-3'; CLDN7 probe 5'- FAM-CGCCCTGTCCGCGGCCTT-BHQ-3'. Primers were designed within different exons and with the probe covering the border of exon 1 and exon 2 to prevent amplification of genomic DNA. Primers and probes were obtained from TAGCopenhagen (Denmark). The endogenous $\beta$-actin control was obtained pre-developed (cat. no.4310881E) from Applied Biosystems. In a validation experiment using a control sample, a dilution series was assayed by the comparative $C_{t}$ method [28] . When $C_{t}$ values were plotted against the logarithmic value of the amount of cDNA added, it was shown that the assays were quantitative over a range of 4096-fold dilution and that the PCR reactions had similar efficiencies provided that a threshold of 0.1 is used for claudin-7 and 0.175 is used for $\beta$-actin. The threshold is a fixed fluorescence signal level above the baseline and the $C_{t}$ value of a sample is determined as the fractional cycle number where the sample's fluorescence signal exceeds the threshold. All samples were quantified in triplicates. The standard deviation on the triplicates was $6 \%$ or less. The standard deviation on repeated measurements of the same sample (the control) in separate experiments was $26 \%$, indicating the day-to-day variation of the assay. Negative controls (where the RNA was not converted into cDNA) and positive controls were included in all runs. Samples for which either the $\beta$-actin or claudin-7 values fell outside the upper or lower limits of the standard curve were excluded from the study.

\section{Western blot analysis}

25-50 mg of frozen tissue was lysed in $500 \mu \mathrm{l}$ PBS containing $1 \%$ Triton $\mathrm{X}-100,0.5 \%$ deoxycholate, and protease inhibitors $(10 \mathrm{mg} / \mathrm{l}$ benzamidine, $2 \mathrm{mg} / \mathrm{l}$ pepstatin A, $2 \mathrm{mg} / \mathrm{l}$ leupeptin, $2 \mathrm{mg} / \mathrm{l}$ antipain, and $2 \mathrm{mg} / \mathrm{l}$ chymostatin). Protein concentrations were measured using BCA $^{\text {TM }}$ Protein Assay Kit (cat. no. 23225, Pierce). Samples were mixed with $2 \times$ SDS PAGE sample buffer containing DTT and boiled for $5 \mathrm{~min}$. The proteins were resolved on $7 \%$ acrylamide gels and transferred to Immobilon-P PVDF membranes (Millipore cat. no. IPVH00010). The blots were blocked with $10 \%$ non-fat dry milk in PBS containing 0.1\% Tween-20 (PBST). PVDF membranes were probed with $0.5 \mu \mathrm{g} / \mathrm{ml}$ rabbit anti-claudin-7 antibody (cat. no. 34-9100, Invitrogen) in $1 \%$ non-fat dry milk in PBST at $4^{\circ} \mathrm{C}$ overnight. Membranes were washed $3 \times 5$ min wash with PBST and incubated 1 hour with $2 \mathrm{ng} / \mathrm{ml}$ goat anti-rabbit secondary antibody conjugated with horseradish peroxidase (HRP) (cat no. 1858415, Pierce) diluted in 1\% non-fat dry milk in PBST. After $3 \times 5$ min wash with PBST the signal was developed using the ECL reagent Supersignal West Femto Maximum Sensitivity Substrate (cat. no. 34095, Pierce) according to the protocol supplied by the manufacturer, and developed with a Fuji LAS1000camera (FujiFilm, Sweden). Blots were stripped in $5 \mathrm{ml}$ Restore $^{\mathrm{TM}}$ Western Blot Stripping Buffer (cat. no. 21059, Pierce) for $15 \mathrm{~min}$ at $37^{\circ} \mathrm{C}$. The above mentioned

Table 1 Characteristics of cases and healthy individuals participating in this study

\begin{tabular}{|c|c|c|c|c|}
\hline $\begin{array}{l}\text { Total number of individuals in } \\
\text { the study }\end{array}$ & $\begin{array}{c}\text { Healthy } \\
\text { individuals } \\
(n=18)\end{array}$ & $\begin{array}{l}\text { Individuals with mild/moderate } \\
\text { dysplasia } \\
(\mathrm{n}=87)\end{array}$ & $\begin{array}{l}\text { Individuals with severe } \\
\text { dysplasia } \\
(\mathrm{n}=13)\end{array}$ & $\begin{array}{l}\text { Individuals with } \\
\text { carcinomas } \\
(n=121)\end{array}$ \\
\hline Number of men & 6 & 61 & 7 & 66 \\
\hline Number of women & 12 & 26 & 6 & 55 \\
\hline Mean age \pm S.D. & $56.8 \pm 4.5$ & $56.9 \pm 3.6$ & $54.9 \pm 3.1$ & $69.5 \pm 12.0$ \\
\hline
\end{tabular}

Comparing the group of healthy individuals with the other groups showed that there were significantly more males in the group with mild dysplasia and CRC $(p<0.001$; Chi Squared test). The mean age is significantly higher among patients with CRC compared to the three other groups ( $p<0.001$; Kruskal-Wallis and Dunn's Multiple Comparison test). 
procedure was repeated, using $0.3 \mu \mathrm{g} / \mathrm{ml}$ primary antibody against $\beta$-actin (cat. no. 8226, Abcam) for one hour at room temperature and $2 \mathrm{ng} / \mathrm{ml}$ goat anti-mouse secondary antibody conjugated with HRP (cat. no. 1858413, Pierce) for one hour.

\section{Immunohistochemistry}

Paraformaldehyde-fixed, paraffin-embedded tissue sections were used for the immunohistochemical analysis. The sections were deparaffinated and antigen retrieval was performed in $10 \mathrm{mM}$ Tris, $0.5 \mathrm{mM}$ EGTA, and $\mathrm{pH}$ 9 by microwave treatment for $18 \mathrm{~min}$ at 600 Watt. Subsequently, after cooling for $20 \mathrm{~min}$ they were rinsed with distilled water. The sections were then treated with $3 \% \mathrm{H}_{2} \mathrm{O}_{2}$ in distilled water for $10 \mathrm{~min}$ and rinsed thoroughly in distilled water, washed in TBS buffer $\mathrm{pH} 7.6$ for $5 \mathrm{~min}$ before a $10 \mathrm{~min}$ incubation with $1 \%$ BSA diluted in TBS buffer. Subsequently, the sections were incubated at room temperature in rabbit anti-claudin-7 antibody (cat. no. 34-9100, Invitrogen) $2 \mu \mathrm{g} / \mathrm{ml}$ in $1 \%$ BSA in TBS buffer for $60 \mathrm{~min}$. The sections were then washed $3 \times 5 \mathrm{~min}$ in TBS buffer, before visualization in EnVision $^{\mathrm{TM}}+$ System HRP/rabbit (cat. no. K-4011, DAKO) for $30 \mathrm{~min}$. After an additional $3 \times 5 \mathrm{~min}$ wash in TBS buffer, DAB (cat. no. K-4011, DAKO) was applied for $10 \mathrm{~min}$. The slides were then rinsed in distilled water and counterstained with Mayer's Haematoxylin for $90 \mathrm{sec}$ and rinsed in water for $5 \mathrm{~min}$ before dehydration and mounting in Pertex ${ }^{\mathrm{TM}}$ Mounting Medium (cat. no. 00801, Histolab).

\section{Statistical analysis}

GraphPad Prism 4 was used for the statistic calculations. The data were not adjusted for gender since the incidence ratio of CRC between the genders is 1:1 in Norway. For all statistical analysis the data was log transformed. Kruskal Wallis and Dunn's Multiple Comparison test were used for statistical comparison of samples from healthy individuals, samples of mild/moderate dysplasias, severe dysplasias and CRC samples. Paired Student's ttest was used for comparison of affected tissue with the matching control sample.

\section{Results}

\section{In-silico analysis of genes co-expressed with the} matriptase gene, ST14

In order to identify genes co-regulated with the ST14 gene, encoding matriptase, an in-silico analysis was performed. The analysis, performed on COXPRESSdb version 4.0 database, shows a network of co-expressed genes including the ST14 gene (Figure 1). Many of these genes are already known to be either inhibitors or substrates of matriptase, such as SPINT1 and SPINT2, encoding the inhibitors of matriptase, HAI-1 and HAI-2

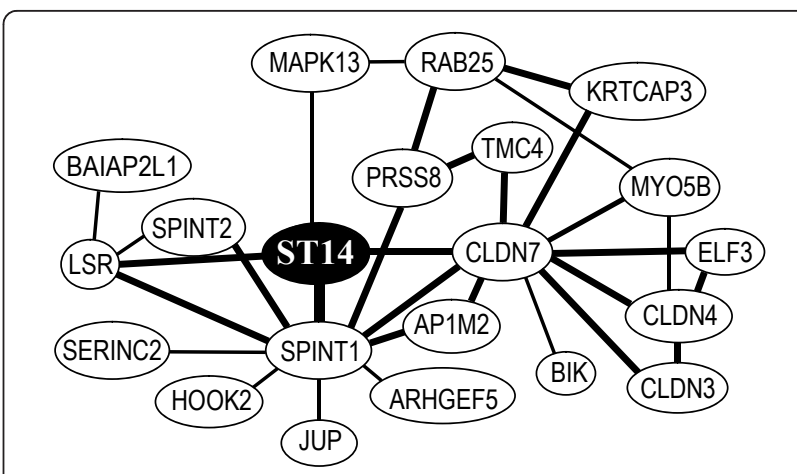

Figure 1 In-silico analysis showing the ST14 co-expressed gene network. The figure shows a modified version of the analysis performed using the COXPRESdb version $4.0 \mathrm{http}: / /$ coxpresdb.jp/. Each gene is represented by a node. Lines between nodes indicate co-expression. The genes with direct ST14 co-expression are marked with a line to the ST14 node. These genes are SPINT1 (encoding HAI-1), CLDN7 (encoding claudin-7), LSR (encoding lipolysis stimulated lipoprotein receptor) and MAPK13 (encoding mitogenactivated protein kinase 13). Bold lines indicate a mutual ratio (MR) below 5 and normal lines indicate a MR between 5 and 30 .

respectively, and the PRSS8 gene encoding the matriptase substrate, prostasin. ST14 has the highest degree of co-regulation with its inhibitor SPINT1 (correlation coefficient $=0.70$ (Pearson's) and a MR $=2.0$ ). In addition to these previously described molecules in the matriptase pathway, we found a new gene, CLDN7, that encodes claudin-7 (correlation coefficient $=0.69$ and $\mathrm{MR}=2.8$ ) to be co-regulated with the ST14 gene. Moreover, the analysis showed that claudin-7 and matriptase have conserved co-expression between human and mouse orthologs. As claudin-7 is involved in the regulation of the epithelial permeability, we found it plausible that the increased epithelial leakiness observed during carcinogenesis could be mediated through a decreased level of claudin-7.

\section{Expression of claudin-7 mRNA during carcinogenesis}

The mRNA levels of claudin-7 were measured by quantitative real-time RT-PCR. We successfully measured claudin-7 mRNA in 15 biopsies from normal mucosa in healthy individuals, in $84 \mathrm{mild} /$ moderate dysplasias with 82 corresponding control samples, 13 severe dysplasias with 11 corresponding control samples, and in 102 colonic carcinomas with 82 corresponding distant and 93 corresponding adjacent control samples (Figure 2 and Table 2).

In general, our analysis showed that the claudin-7 mRNA levels were decreased as an early event in the carcinogenesis, as the claudin-7 mRNA level is decreased already in the mild/moderate dysplasias. The decrease was maintained in the severe dysplasias and the carcinomas. The levels of claudin-7 mRNA in 


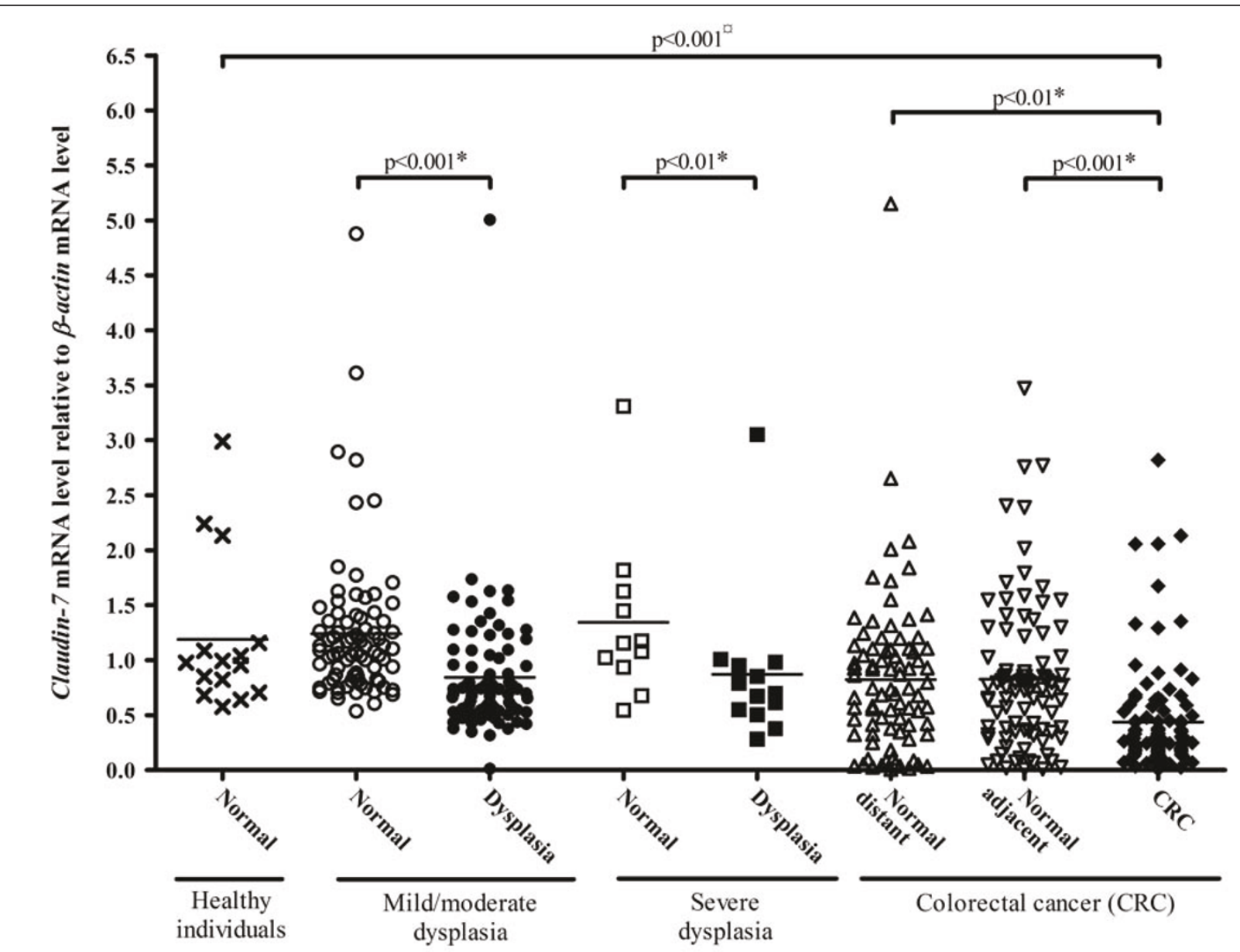

Figure 2 Claudin-7 mRNA levels in healthy individuals, individuals with dysplasia and individuals with carcinomas as determined by real-time RT-PCR. Samples from healthy individuals (cross), normal (open circle) and affected tissue (filled circle) from individuals with mild/ moderate dysplasia, normal (open square) and affected tissue (filled square) from individuals with severe dysplasia, normal adjacent (open triangle), normal distant (open triangle) and carcinomatous tissue (filled diamond) from colorectal cancer patients were analysed for claudin-7 mRNA levels relative to the $\beta$-actin mRNA levels. The horizontal line represents the mean values. The $p$-value indicated with a $x$ is calculated using Kruskal Wallis and Dunn's Multiple Comparison test and p-values marked with a * are calculated using Paired Student's t-test.

normal mucosa from individuals with dysplasia or carcinomas were not affected (Table 2). A highly significant 2.7 -fold reduction in the claudin- 7 mRNA level was found, when comparing the biopsies from healthy individuals with the samples of carcinomas $(p<0.001$,
Kruskal Wallis and Dunn's Multiple Comparison test). Comparing affected and normal tissue from the CRC patients using Paired Student's t-test showed a 2.0-fold reduction (95\% confidence interval (CI): 1.4-2.9) and a 1.7-fold reduction (CI: 1.2-2.5) in expression level for

Table 2 Claudin-7 mRNA levels in normal and affected tissues normalised to the $\beta$-actin mRNA level

\begin{tabular}{|c|c|c|c|c|c|}
\hline Variable & $\begin{array}{l}\text { mRNA level in normal tissue } \\
\text { Mean } \pm \text { S.D. }\end{array}$ & $\mathrm{P}^{\mathrm{a}}$ & $\begin{array}{l}\text { mRNA level in adenomas/carcinomas } \\
\text { Mean } \pm \text { S.D. }\end{array}$ & $P^{a}$ & $\mathrm{P}^{\mathrm{b}}$ \\
\hline Healthy individuals & $1.19 \pm 0.70$ & & & & \\
\hline Individuals with mild/moderate dysplasia & $1.24 \pm 0.67$ & NS & $0.84 \pm 0.58$ & NS & $<0.001$ \\
\hline Individuals with severe dysplasia & $1.34 \pm 0.75$ & NS & $0.87 \pm 0.69$ & NS & $<0.01$ \\
\hline Cancer patients & $\begin{array}{l}0.82 \pm 0.73 \text { (distant) } \\
0.83 \pm 0.66 \text { (adjacent) }\end{array}$ & $\begin{array}{l}\text { NS } \\
\text { NS }\end{array}$ & $0.44 \pm \underset{\sim}{\prime \prime} 0.48$ & $<0.001$ & $\begin{array}{l}<0.01 \\
<0.001\end{array}$ \\
\hline
\end{tabular}

NS = not significant.

a) $\mathrm{p}$ value for the comparison to the expression levels in tissue from healthy individuals using Kruskal Wallis and Dunn's Multiple Comparison test.

b) $\mathrm{p}$ value for the comparison of the expression levels in normal and affected tissue from the same individual using Paired Student's t-test. 
normal adjacent $(\mathrm{p}<0.001)$ and normal distant $(\mathrm{p}<$ 0.01 ) samples, respectively. A similar analysis on individuals with mild/moderate or severe dysplasia showed a 1.6-fold (CI: 1.4-1.9; p < 0.001) and a 1.5-fold (CI: 1.21.9; $\mathrm{p}<0.01$ ) reduction in the claudin-7 mRNA levels, respectively. We found no correlation between the claudin-7 mRNA levels and age, gender, high risk/low risk status of the adenoma, or Duke's stage of the carcinoma (data not shown).

\section{Expression and localisation of claudin-7 protein in colorectal cancers}

Carcinoma tissue and normal mucosa from five CRC patients were extracted and the proteins were analysed on Western blots (Figure 3). Only one distinct band of approximately $22 \mathrm{kDa}$ was detected using an antibody against claudin-7. This is in accordance with the expected size of claudin-7 [29]. Immunohistochemical stainings were performed on adenomas from four individuals without any history of carcinomas and on CRC tissue and normal mucosa from five CRC patients (Figure 4 and additional files 1). All stainings of adenomas showed essentially the same, and a representative example is shown in Figure 4. An intense claudin-7 reaction was seen in histologically normal appearing mucosa (Figure 4B and 4C) whereas dysplastic tissue

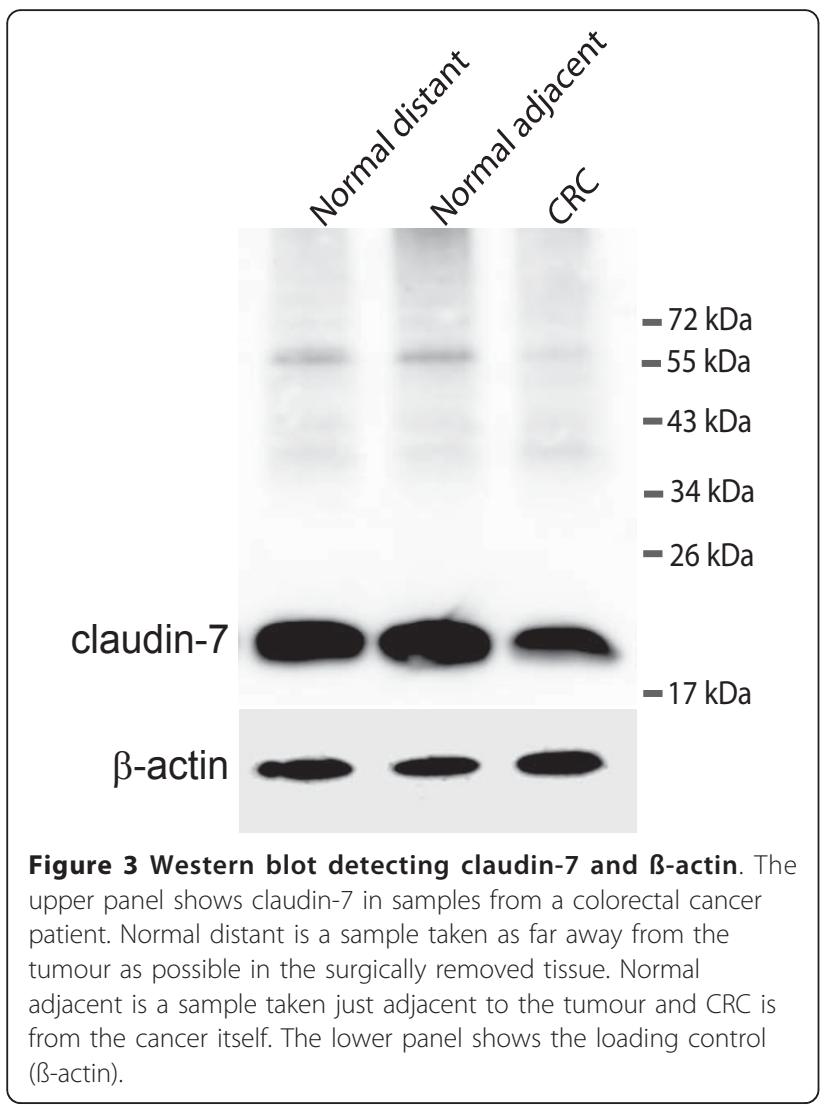

ranged from almost no staining to staining similar to the normal mucosa (Figure 4B and 4D). Stainings of the five colorectal cancer samples also showed essentially the same and is shown in figure 4 and additional file 2. Histologically normal mucosa from cancer patients also displayed an intense claudin-7 reaction that was detected from the transitional zone (Figure 4F and $4 \mathrm{G}$ ). In the cancerous tissue, the staining was reduced or almost absent (Figure $4 \mathrm{~F}$ and $4 \mathrm{H}$ ). These observations are consistent with the claudin-7 mRNA levels obtained in this study. The normal appearing mucosa from the transitional zone showed, at high magnification, staining for claudin-7. The staining was mainly localised at the basolateral plasma membranes of the surface epithelial cells (Figure 4C and 4G), whereas the ademomatous and carcinomatous tissue showed faint, patchy staining of the epithelial strands of tumor tissue (Figure 4B and 4F).

\section{Discussion}

In the present study we found a correlation between the claudin-7 mRNA level, as determined by real-time RTPCR, and the claudin- 7 protein level, as determined by immunohistochemistry in normal mucosa, adenomas and carcinomas of the colon. This suggests that claudin-7 mRNA level reflects the protein level. Our results suggest that a decrease in the level of claudin-7 occurs already in mild/moderate dysplasias as an early event in carcinogenesis and that the decreased level is maintained in severe dysplasias and in the CRC tissue. To our knowledge this is the first analysis of claudin-7 mRNA expression in colorectal mucosa from healthy individuals and from individuals with colorectal dysplasia. Previous studies have compared normal and cancerous colorectal tissue from the same individual. The group of Nakayama et al. [24] found a lower expression of claudin-7 in $80 \%$ of invasive CRCs $(n=90)$ than in non-neoplastic tissue, which corresponds well with our findings. However, our observations are in contrast to the studies by Kuhn et al. [25] and Darido et al. [30], who both found higher expression of claudin-7 protein in CRC tissue as compared to normal tissue from the same individual, using immunohistochemistry alone.

For other types of cancer, a number of studies have compared claudin-7 expression in malignant tissue and normal tissue from patients. They find that claudin- 7 is down-regulated in head and neck cancer [31], nasopharyngeal cancer [32], squamous cell carcinomas of the oesophagus [33] and in breast cancer [29,34,35]. However, claudin-7 seems to be up-regulated in gastric cancer [36] and ovarian cancer [37]. In squamous cell carcinomas of the oesophagus, reduced expression of claudin-7 correlates with invasion and metastasis [33]. 

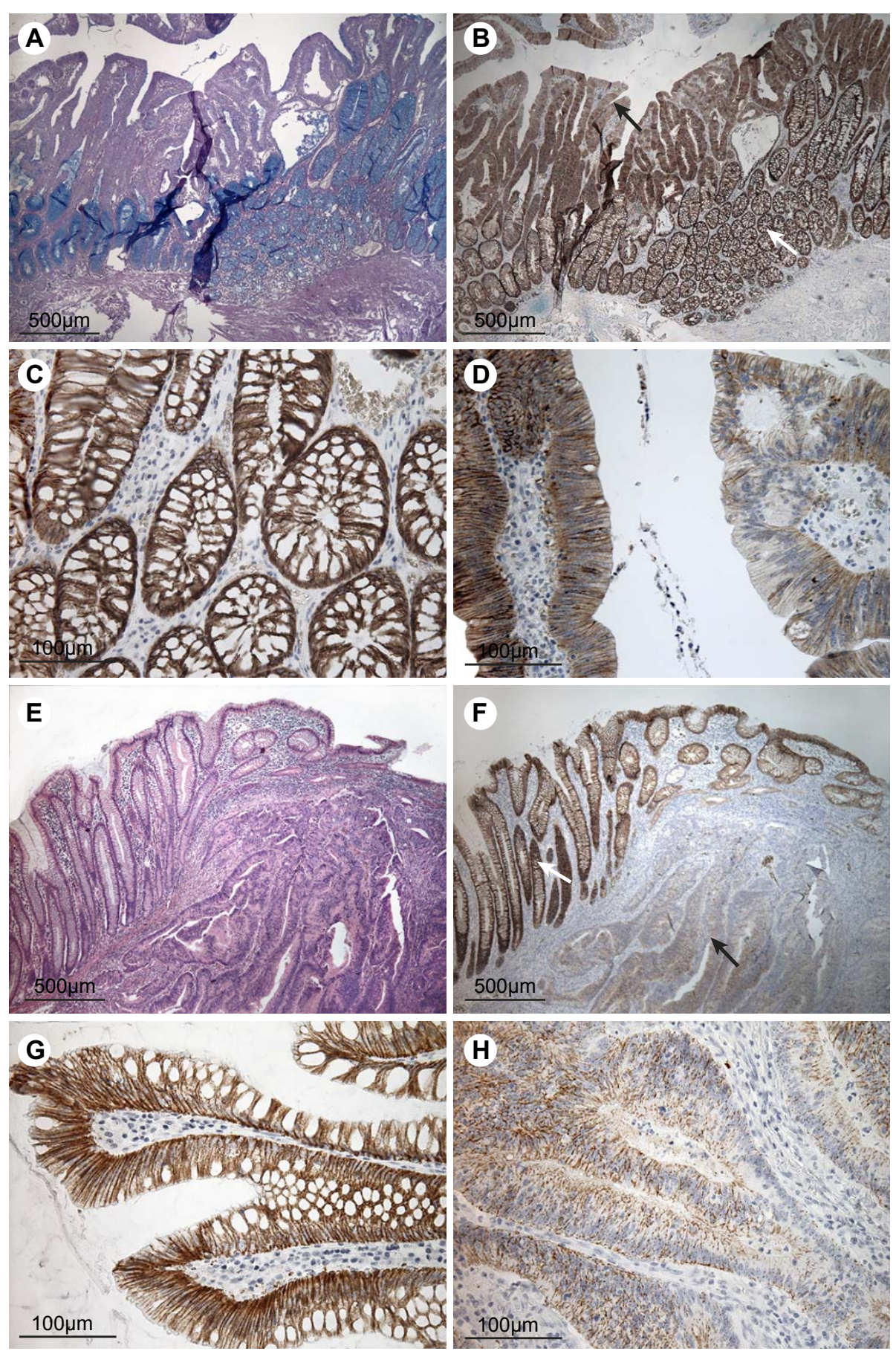

Figure 4 Immunohistochemical staining for claudin-7 in colorectal adenomas, carcinomas and adjacent normal tissue. The top four pictures are taken from an individual with dysplasia but no record of carcinoma and the bottom four pictures are from a patient with colorectal cancer. A) Tissue section including both normal mucosa and dysplastic tissue, stained with PAS/Alcian. B) Neighbouring tissue section stained for claudin-7. The white arrow indicates mucosa of normal appearance and the black arrow indicates dysplastic tissue. C) High magnification of the normal mucosa from B, showing staining mainly at the basolateral cell membranes of the epithelial cells. D) High magnification of the dysplastic tissue from B showing a patchy staining pattern with areas of low and normal staining. E) Tissue section with cancerous tissue to the right and normal mucosa to the left, stained with Hematoxylin and Eosin. F) Neighbouring tissue section stained for claudin-7. The white arrow indicates the mucosa with normal appearance. The black arrow points out carcinomatous tissue. G) High magnification of histologically normally appearing mucosa from $F$, showing staining mainly localised to the basolateral cell membranes of the surface epithelial cells. H) High magnification of carcinomatous tissue showing faint, patchy staining of the epithelial strands of tumour tissue. Scale bars: $500 \mu m(A+B+E+$ F), $100 \mu \mathrm{m}(C+D+G+H)$. 
Likewise, reduced claudin-7 levels correlates with the histological grading of breast carcinomas [29,34].

Our in-silico analysis suggests that dysregulated matriptase may affect the epithelial tightness during carcinogenesis by modulating the expression of claudin-7. We have previously shown that the mRNA expression levels of matriptase (ST14) and HAI-1 (SPINT1) are dysregulated during colorectal carcinogenesis in a cohort very similar to the one used in this study $[21,22]$. Comparison between the mRNA levels of claudin-7 (this study) and matriptase mRNA levels in the similar cohort [21] shows that they have a virtually identical pattern, confirming that mRNA expression of matriptase and claudin-7 are closely correlated.

This suggests that the genes encoding matriptase and claudin-7 may be regulated by the same transcription factors. Alternatively, the expression levels of matriptase may affect the expression levels of claudin-7. We attempted to analyse whether an over-expression of matriptase in the colonic adenocarcinoma cell line Caco-2 influenced the claudin-7 mRNA level. However, these experiments were inconclusive as manipulation of matriptase expression is cytotoxic (Vogel et al., unpublished results). Further investigations are needed to clarify this point.

It has recently been shown that siRNA silencing of matriptase in Caco-2 cells resulted in up-regulation of the claudin-2 protein level [20]. Claudin-2 is a poreforming claudin closely related to claudin-7 [38]. Up-regulation of claudin-2 thus results in increased epithelial leakiness. Claudin-2 is heavily up-regulated in colorectal cancer tissue compared to normal tissue from the same individual $[39,40]$. There have been no reports about the expression level of claudin-2 in dysplastic tissue. The increased epithelial permeability seen in colorectal dysplastic tissue is thus probably the result of dysregulation of a number of claudins, some of which may depend on matriptase expression or activity.

In esophageal squamous cell carcinoma cells, overexpression of claudin-7 resulted in more adhesive and less invasive cells, whereas knockdown of claudin-7 using a small interfering RNA approach led to enhanced invasion into a three-dimensional matrix [41]. This suggests that claudin-7 down-regulation does indeed contribute to drive carcinogenesis.

\section{Conclusions}

In conclusion, the present study shows that the level of claudin-7 is decreased as an early event in colorectal carcinogenesis and may play a role by decreasing epithelial tightness, thereby allowing carcinogens to enter the tissue.

\section{Additional material}

Additional file 1: Immunohistochemical staining for claudin-7 in dysplastic tissue. The figure shows sections from three individuals with dysplasias. Each individual is represented in the rows marked with the numbers id\#62, id\#488 and id\#536. The left column shows an area in the biopsy with mucosa of normal histological appearance, whereas the right column shows an area of dysplasia. Scalebars: $100 \mu \mathrm{m}$.

Additional file 2: Immunohistochemical staining for claudin-7 in colorectal cancer. The figure represents colorectal cancer sections from four patients. Each individual is represented in the rows marked with the numbers patient $A$, patient $C$, patient $D$ and patient $O$. The left column shows an area in the biopsy with mucosa of normal histological appearance, whereas the right column shows an area of cancerous tissue. Scalebars: $100 \mu \mathrm{m}$

\section{Acknowledgements}

We thank Christel Halberg for kind technical help and assistance performing the mRNA analysis and Margit Bæksted for performing the immunohistochemical stainings. This work was supported by The Norwegian Cancer Society, Telemark University College, the Norwegian Colorectal Cancer Prevention (NORCCAP) study, Eastern Norway Regional Health Authority, The Cluster of Cell Biology at the University of Copenhagen, The Harboe Foundation, The Augustinus Foundation, The Brothers Hartmanns Foundation, The A.P. Møllers Foundation for the Advancement of Medical Science and the Lundbeck Foundation.

\section{Author details}

${ }^{1}$ Department of Cellular and Molecular Medicine, Faculty of Health Science, University of Copenhagen, Denmark. ${ }^{2}$ Department of Biology, Faculty of Science, University of Copenhagen, Copenhagen, Denmark. ${ }^{3}$ Department of Medical Anatomy, Faculty of Health Science, University of Copenhagen, Copenhagen, Denmark. ${ }^{4}$ Department of Pathology, Diagnostic Center, Copenhagen University Hospital, Copenhagen, Denmark. ${ }^{5}$ Department of Pathology, Oslo University Hospital, Oslo, Norway. ${ }^{6}$ Department of Oncology, Oslo University Hospital, Oslo, Norway. ${ }^{7}$ Department of Gastroenterological Surgery Oslo University Hospital, Oslo, Norway. ${ }^{8}$ Faculty of Medicine, University of Oslo, Oslo, Norway. ${ }^{9}$ Department of Genetics, Institute for Cancer Research, Oslo University Hospital, Oslo, Norway. ${ }^{10}$ Department of Environmental and Health Studies, Telemark University College, Bø, Norway.

\section{Authors' contributions}

SF and LV conceived the idea of the study. SF performed the in-silico analysis. EHK, IMBL, EJ, TI and KMT established the NORCCAP and Ulleval colorectal cancer cohort (KAM cohort). LV and EHK extracted the RNA. LV validated primers and probes. JB did the western blotting. ESR performed the immunohistochemical stainings. SSP took the pictures. IMBL performed and evaluated the sections of immunohistochemical analysis. JB analysed the data, prepared the figures and performed the statistical analysis. JB drafted the first manuscript. All authors helped with the draft, read and approved the final version.

\section{Competing interests}

The authors declare that they have no competing interests.

Received: 27 September 2010 Accepted: 10 February 2011 Published: 10 February 2011

\section{References}

1. Soler AP, Miller RD, Laughlin KV, Carp NZ, Klurfeld DM, Mullin JM: Increased tight junctional permeability is associated with the development of colon cancer. Carcinogenesis 1999, 20:1425-1431.

2. Angelow S, Ahlstrom R, Yu AS: Biology of claudins. Am J Physiol Renal Physiol 2008, 295:F867-F876.

3. Martin TA, Jiang WG: Loss of tight junction barrier function and its role in cancer metastasis. Biochim Biophys Acta 2009, 1788:872-891.

4. Gonzalez-Mariscal L, Betanzos A, Nava P, Jaramillo BE: Tight junction proteins. Prog Biophys Mol Biol 2003, 81:1-44. 
5. Tsukita S, Furuse M, Itoh M: Multifunctional strands in tight junctions. Nat Rev Mol Cell Biol 2001, 2:285-293.

6. Krause G, Winkler L, Mueller SL, Haseloff RF, Piontek J, Blasig IE: Structure and function of claudins. Biochim Biophys Acta 2008, 1778:631-645.

7. Ouban A, Ahmed AA: Claudins in human cancer: a review. Histol Histopathol 2010, 25:83-90.

8. Will C, Fromm M, Muller D: Claudin tight junction proteins: novel aspects in paracellular transport. Perit Dial Int 2008, 28:577-584.

9. Oliveira SS, Morgado-Diaz JA: Claudins: multifunctional players in epithelial tight junctions and their role in cancer. Cell Mol Life Sci 2007, 64:17-28.

10. Hou J, Gomes AS, Paul DL, Goodenough DA: Study of claudin function by RNA interference. J Biol Chem 2006, 281:36117-36123.

11. Alexandre MD, Jeansonne BG, Renegar RH, Tatum R, Chen YH: The first extracellular domain of claudin-7 affects paracellular $\mathrm{Cl}$ - permeability. Biochem Biophys Res Commun 2007, 357:87-91.

12. Tatum R, Zhang Y, Salleng K, Lu Z, Lin JJ, Lu Q, et al: Renal salt wasting and chronic dehydration in claudin-7-deficient mice. Am J Physiol Renal Physiol 2010, 298:F24-F34.

13. Rosenthal R, Milatz S, Krug SM, Oelrich B, Schulzke JD, Amasheh S, et al: Claudin-2, a component of the tight junction, forms a paracellular water channel. J Cell Sci 2010, 123:1913-1921.

14. List K, Szabo R, Molinolo A, Nielsen BS, Bugge TH: Delineation of matriptase protein expression by enzymatic gene trapping suggests diverging roles in barrier function, hair formation, and squamous cell carcinogenesis. American Journal of Pathology 2006, 168:1513-1525.

15. List K, Szabo R, Molinolo A, Sriuranpong V, Redeye V, Murdock T, et al: Deregulated matriptase causes ras-independent multistage carcinogenesis and promotes ras-mediated malignant transformation. Genes Dev 2005, 19:1934-1950.

16. Szabo R, Hobson JP, Christoph K, Kosa P, List K, Bugge TH: Regulation of cell surface protease matriptase by HAl2 is essential for placental development, neural tube closure and embryonic survival in mice. Development 2009, 136:2653-2663.

17. Szabo R, Molinolo A, List K, Bugge TH: Matriptase inhibition by hepatocyte growth factor activator inhibitor-1 is essential for placental development. Oncogene 2007, 26:1546-1556.

18. List K, Haudenschild CC, Szabo R, Chen W, Wahl SM, Swaim W, et al Matriptase/MT-SP1 is required for postnatal survival, epidermal barrier function, hair follicle development and thymic homeostasis. Oncogene 2002. 21:3765-3779.

19. List K, Kosa P, Szabo R, Bey AL, Wang CB, Molinolo A, et al: Epithelial integrity is maintained by a matriptase-dependent proteolytic pathway. Am J Pathol 2009, 175:1453-1463.

20. Buzza MS, Netzel-Arnett S, Shea-Donohue T, Zhao A, Lin CY, List K et al: Membrane-anchored serine protease matriptase regulates epithelial barrier formation and permeability in the intestine. Proc Natl Acad Sci USA 2010, 107:4200-4205.

21. Vogel LK, Saebo M, Skjelbred CF, Abell K, Pedersen ED, Vogel U, et al: The ratio of Matriptase/HAl-1 mRNA is higher in colorectal cancer adenomas and carcinomas than corresponding tissue from control individuals. BMC Cancer 2006, 6:176.

22. Selzer-Plon J, Bornholdt J, Friis S, Bisgaard HC, Lothe IM, Tveit KM, et al: Expression of prostasin and its inhibitors during colorectal cancer carcinogenesis. BMC Cancer 2009, 9:201.

23. Coyne CB, Gambling TM, Boucher RC, Carson JL, Johnson LG: Role of claudin interactions in airway tight junctional permeability. Am J Physiol Lung Cell Mol Physiol 2003, 285:L1166-L1178.

24. Nakayama F, Semba S, Usami Y, Chiba H, Sawada N, Yokozaki H: Hypermethylation-modulated downregulation of claudin-7 expression promotes the progression of colorectal carcinoma. Pathobiology 2008, 75:177-185.

25. Kuhn $\mathrm{S}$, Koch M, Nubel T, Ladwein M, Antolovic D, Klingbeil P, et al: A complex of EpCAM, claudin-7, CD44 variant isoforms and tetraspanins promotes colorectal cancer progression. Mol Cancer Res 2007, 5:553-567.

26. Obayashi T, Hayashi S, Shibaoka M, Saeki M, Ohta H, Kinoshita K: COXPRESdb: a database of coexpressed gene networks in mammals. Nucleic Acids Res 2008, 36:D77-D82.

27. Gondal G, Grotmol T, Hofstad B, Bretthauer M, Eide TJ, Hoff G: The Norwegian Colorectal Cancer Prevention (NORCCAP) screening study: baseline findings and implementations for clinical work-up in age groups 50-64 years. Scand J Gastroenterol 2003, 38:635-642.

28. Johnson MR, Wang KS, Smith JB, Heslin MJ, Diasio RB: Quantitation of dihydropyrimidine dehydrogenase expression by real-time reverse transcription polymerase chain reaction. Analytical Biochemistry 2000, 278:175-184

29. Kominsky SL, Argani P, Korz D, Evron E, Raman V, Garrett E, et al: Loss of the tight junction protein claudin-7 correlates with histological grade in both ductal carcinoma in situ and invasive ductal carcinoma of the breast. Oncogene 2003, 22:2021-2033.

30. Darido C, Buchert M, Pannequin J, Bastide P, Zalzali H, Mantamadiotis T, et al: Defective claudin-7 regulation by Tcf-4 and Sox-9 disrupts the polarity and increases the tumorigenicity of colorectal cancer cells. Cancer Res 2008, 68:4258-4268.

31. Al Moustafa AE, Alaoui-Jamali MA, Batist G, Hernandez-Perez M, Serruya C, Alpert $L$, et al: Identification of genes associated with head and neck carcinogenesis by CDNA microarray comparison between matched primary normal epithelial and squamous carcinoma cells. Oncogene 2002, 21:2634-2640.

32. Hsueh C, Chang YS, Tseng NM, Liao CT, Hsueh S, Chang JH, et al: Expression pattern and prognostic significance of claudins 1, 4, and 7 in nasopharyngeal carcinoma. Hum Pathol 2010, 41:944-950.

33. Usami Y, Chiba H, Nakayama F, Ueda J, Matsuda Y, Sawada N, et al: Reduced expression of claudin-7 correlates with invasion and metastasis in squamous cell carcinoma of the esophagus. Hum Pathol 2006, 37:569-577.

34. Sauer T, Pedersen MK, Ebeltoft K, Naess O: Reduced expression of Claudin7 in fine needle aspirates from breast carcinomas correlate with grading and metastatic disease. Cytopathology 2005, 16:193-198.

35. Tokes AM, Kulka J, Paku S, Mathe M, Paska C, Lodi C, et al: The expression of five different claudins in invasive breast carcinomas: comparison of pT1pN1 and pT1pN0 tumors. Pathol Res Pract 2005, 201:537-544.

36. Rendon-Huerta E, Teresa F, Teresa GM, Xochitl GS, Georgina AF, Veronica ZZ, et al: Distribution and expression pattern of claudins 6, 7, and 9 in diffuse- and intestinal-type gastric adenocarcinomas. J Gastrointest Cancer 2010, 41:52-59.

37. Tassi RA, Bignotti E, Falchetti M, Ravanini M, Calza S, Ravaggi A, et al: Claudin-7 expression in human epithelial ovarian cancer. Int J Gynecol Cancer 2008, 18:1262-1271.

38. Rosenthal R, Milatz S, Krug SM, Oelrich B, Schulzke JD, Amasheh S, et al: Claudin-2, a component of the tight junction, forms a paracellular water channel. J Cell Sci 2010, 123:1913-1921.

39. Aung PP, Mitani $Y$, Sanada $Y$, Nakayama $H$, Matsusaki K, Yasui W: Differential expression of claudin-2 in normal human tissues and gastrointestinal carcinomas. Virchows Arch 2006, 448:428-434.

40. Kinugasa T, Huo Q, Higashi D, Shibaguchi H, Kuroki M, Tanaka T, et al: Selective up-regulation of claudin-1 and claudin- 2 in colorectal cancer. Anticancer Res 2007, 27:3729-3734.

41. Lioni M, Brafford P, Andl C, Rustgi A, El-Deiry W, Herlyn M, et al: Dysregulation of claudin-7 leads to loss of E-cadherin expression and the increased invasion of esophageal squamous cell carcinoma cells. Am J Pathol 2007, 170:709-721.

Pre-publication history

The pre-publication history for this paper can be accessed here: http://www.biomedcentral.com/1471-2407/11/65/prepub

doi:10.1186/1471-2407-11-65

Cite this article as: Bornholdt et al.: The level of claudin- 7 is reduced as an early event in colorectal carcinogenesis. BMC Cancer 2011 11:65. 